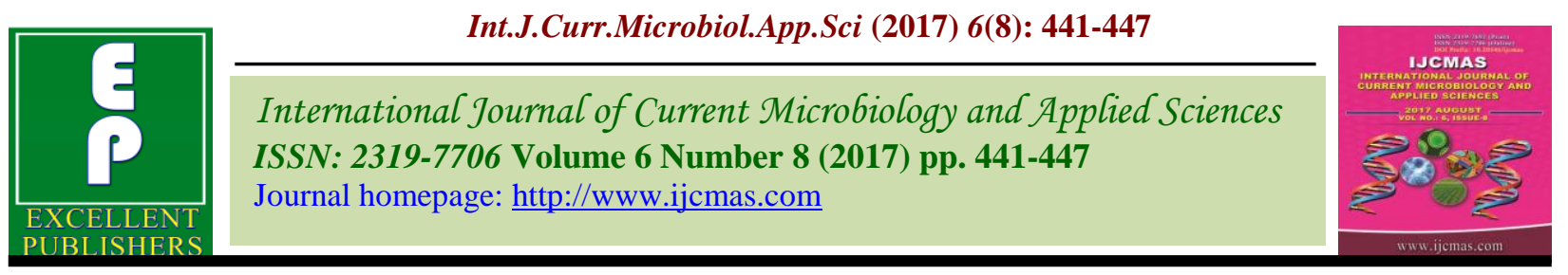

Original Research Article https://doi.org/10.20546/ijcmas.2017.608.058

\title{
Isolation and Identification of Bacillus cereus from Fish and their Handlers from Jammu, India
}

\author{
U. Rasool, Ajaz Ahmad", G.A. Badroo, Mir Mudasir, S. Fayaz and R. Mustafa \\ Department of Food Technology, Doon Valley Institute of Engineering and Technology, \\ Karnal-132001, Haryana, India \\ *Corresponding author
}

\section{A B S T R A C T}

Keywords

Bacillus cereus,

Enterotoxigenic,

Fish, Gram staining, PEMBA.

Article Info

Accepted:

04 June 2017

Available Online:

10 August 2017
The aim of the study is to know the occurrence of B. cereus and level of contamination with $B$. cereus in fish from Jammu region. In this study 140 samples were collected from various parts of Jammu. Out of 140 samples $44(31.42 \%)$ samples showed characteristic peacock blue colored colonies on selective PEMBA. On Gram staining all these isolates were Gram positive rods and sometimes spores were also seen. Biochemical characterization was done to identify $B$. cereus isolates was done. Forty four (44) isolates were subjected to various biochemical tests but only 39 $(27.85 \%)$ isolates showed characteristic biochemical features as that of $B$. cereus. All the 39 isolates were positive for catalase test, citrate utilization test and motility. Thirty seven $(94.87 \%)$ B. cereus isolates hydrolyzed starch and produces beta-hemolysis on sheep blood agar. All the 39 Bacillus cereus isolates were positive for nitrate reduction test and VogesProskauer test but negative for oxidase test.

\section{Introduction}

Bacillus cereus (B. cereus), a Gram-positive, rod shaped endospore-forming bacteria is an important cause of food-borne illness in humans and is frequently involved in foodborne outbreaks (Ryan, 2004). It is a facultative anaerobic organism belonging to genus Bacillus. The genus Bacillus is ubiquitous in nature because it does not have complex nutrient requirements. Bacillus group is composed of B. cereus, B. anthracis, $B$. thuringiensis and $B$. mycoides based on the similarity in $16 \mathrm{~S}$ rRNA sequence (Seki T).
Bacterial counts in excess of $10^{5}-10^{6} / \mathrm{g}$ have been encountered in food suspected of causing illness. The resistance of its spores to adverse environmental conditions has enabled it to get distributed widely in the environment. Because of its ubiquitous nature, it easily spreads to the foods of plant origin and through cross contamination to other foods. The study of B. cereus in relation to food has gained significance in the light of its ability to form heat resistant endospores and capacity to grow and produce toxins in a 
wide variety of foods. Transmission electron microscopy of the vegetative cells reveals a cytoplasmic membrane surrounding the cellular content. In addition, some strains contain an outermost crystalline surface protein (Kotiranta et al., 1998, 2000). The aim of the present investigation is to study the incidence and level of contamination with $B$. cereus in fish from Jammu region.

\section{Materials and Methods}

A total of 140 samples of fish comprising of gills of fresh water fishes as such or swabs aseptically taken there form, were collected in sterile zipped plastic sachet at various wholesale and retail fish outlets from markets in Jammu city.

\section{Isolation and identification of $B$. cereus}

\section{Isolation}

Polymyxin - pyruvate - Egg yolk - Mannitol Bromothymol blue Agar (PEMBA) media was used for isolation of $B$. cereus. The samples were processed as per the method described by Shinagawa (1990). The samples were inoculated into brain heart infusion broth (BHIB) containing polymyxin (100 units $/ \mathrm{ml})$. The BHIB tubes were then incubated at $37^{\circ} \mathrm{C}$ for $24-48$ hours. After enrichment a loopful was streaked on PEMBA plates and incubated at $37^{\circ} \mathrm{C}$ for 24 $\mathrm{h}$. The fimbriate peacock blue coloured colonies $(3-5 \mathrm{~mm})$ surrounded by blue zone of egg yolk hydrolysis against green/greenish yellow back ground were presumed to be $B$. cereus. The presumed isolates were preserved on nutrient agar slants for further characterization.

\section{Identification and confirmation}

All presumptive colonies of $B$. cereus were purified and subjected to morphological and biochemical tests for identification and confirmation as described in Bacteriological Analytical Manual of United States, Food and Drug Administration (Rhodehamel and Harmon 2001 and Bergey's Manual of Systemic Bacteriology (Clause and Berkeley 1986). In addition to this molecular identification of the presumptive isolates was carried out.

\section{Morphology}

Gram stained smears were prepared from slants and examined microscopically. $B$. cereus appeared as large Gram positive bacilli in short to long chains, whereas, spores were ellipsoidal, central to sub terminal and did not swell the sporangium.

\section{Biochemical characterization of $B$. cereus isolates}

\section{Catalase test}

The presumptive B. cereus isolates were tested for their catalase activity. Briefly, a drop of 3 percent hydrogen peroxide $\left(\mathrm{H}_{2} \mathrm{O}_{2}\right)$ was taken on a clean glass slide and the presumed colony was mixed with it. The formation of gas bubbles was taken as positive reaction.

\section{Oxidase test}

A loopfull of bacterial growth was rubbed using a sterile platinum loop on oxidase disc (Hi Media Ltd., Mumbai) in a sterile Petri plate. Development of deep purple blue or mauve colour within $10 \mathrm{sec}$ was considered as positive and no color change was taken as negative reaction.

\section{Voges-Proskauer test}

In a tube containing $2 \mathrm{ml}$ of sterile glucose phosphate peptone water (Hi Media Ltd., 
Mumbai) a loopful of young broth culture (18-24 h) was inoculated and incubated at $37^{\circ} \mathrm{C}$ for $48 \mathrm{hrs}$. After $48 \mathrm{hrs}, 0.2 \mathrm{ml} 40$ per cent potassium hydroxide was added followed by $0.6 \mathrm{ml}$ of $\alpha$-napthol solution. The development of pink or crimson colour was recorded as positive reaction while no colour change was the negative reaction.

\section{Nitrate reduction test}

Sterile nitrate broth (Hi Media Ltd., Mumbai) $(0.5 \mathrm{ml})$ was inoculated with a heavy growth of the test organism and incubated at $37^{\circ} \mathrm{C}$ for 24 hrs. Subsequently, one drop each of sulphanilic acid and the $\alpha$-naphthylamine reagent was added to the test culture in broth.

The development of red colour within one minute was taken as positive reaction. The tube that did not show red colour within five minutes was treated with zinc powder and allowed to stand for $5 \mathrm{~min}$. In such cases, the development of red colour indicated the presence of nitrate in the medium, as it was not reduced to nitrite by the test organism.

\section{Starch hydrolysis test}

A loopful of bacterial growth was streaked on starch agar plate and incubated at $37^{\circ} \mathrm{C}$ for 48 hrs. After 2 days of incubation, the plate was flooded with iodine solution. Iodine turns blue or black in the presence of starch. A clearing around the bacterial growth indicated that the organism has hydrolysed starch.

\section{Citrate utilization test}

A loopful of bacterial growth was streaked on Simmon's citrate agar slants and incubated at $37^{\circ} \mathrm{C}$ for $24 \mathrm{hrs}$. The development of blue colour due to utilization of citrate as a carbon source by the organism was taken as positive reaction while green colour was considered as negative reaction.

\section{Motility test}

The test was performed to observe the motility of $B$. cereus having peritrichous flagella. $B$. cereus motility medium was inoculated by stabbing down the centre with a $24 \mathrm{~h}$ culture suspension of presumptive isolate. The tubes were incubated for 18-24 h at $30^{\circ} \mathrm{C}$ and examined for diffuse type of growth away from stab line.

\section{Haemolytic activity test}

The test was performed on all B. cereus isolates for the production of haemolysis on sheep blood agar. A loopful of culture was streaked on blood agar plate and incubated for $24 \mathrm{~h}$ at $37^{\circ} \mathrm{C}$ and observed for haemolytic zones around the colonies. B. cereus cultures are usually strongly haemolytic and produced zones of complete b-haemolysis surrounding the growth.

\section{Results and Discussion}

In the present study, a total of 140 samples of fish from places in and around Jammu were analysed for the presence of $B$. cereus. Out of 140 samples 44 (31.42\%) samples showed characteristic peacock blue coloured colonies on selective PEMBA (Figure 1).

All these isolates were Gram positive rods and sometimes spores were also seen (Figures 2 and 3). Biochemical characterization to identify B. cereus isolates was done. Forty four (44) isolates were subjected to various biochemical tests but only $39(27.85 \%)$ isolates showed characteristic biochemical features as that of B. cereus.

All the 39 isolates were positive for catalase test, citrate utilization test (Figure 4) and motile (Figure 5). 37 (94.87\%) B. cereus isolates also hydrolyzed starch (Figure 6) and produces beta-hemolysis on sheep blood agar 
(Figure 7). All the 39 B. cereus isolates were positive for nitrate reduction test (Figure 8) and Voges-Proskauer test (Figure 9) and but negative for oxidase test.

Fig.1 B. cereus colonies on PEMBA

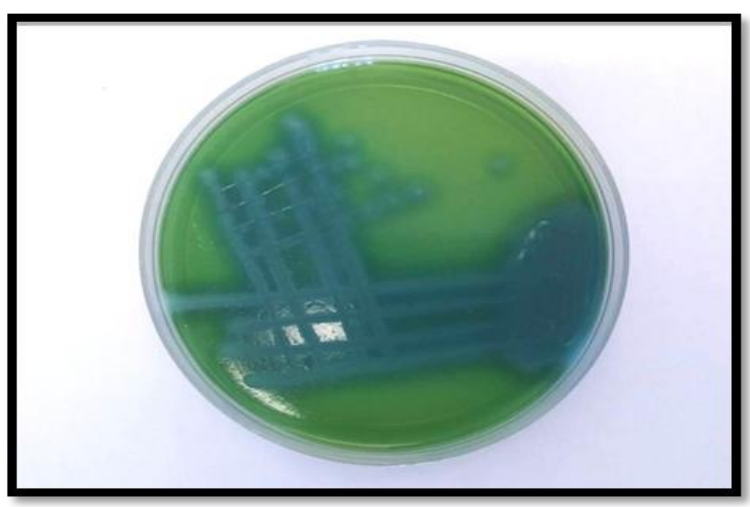

Fig.2 Gram staining of B. cereus (Gram positive rods)

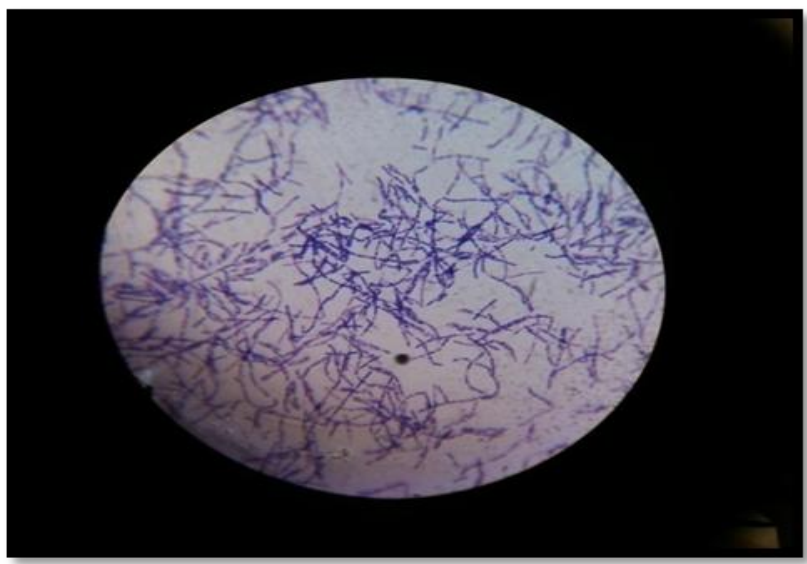

Fig.3 Spores of B. cereus

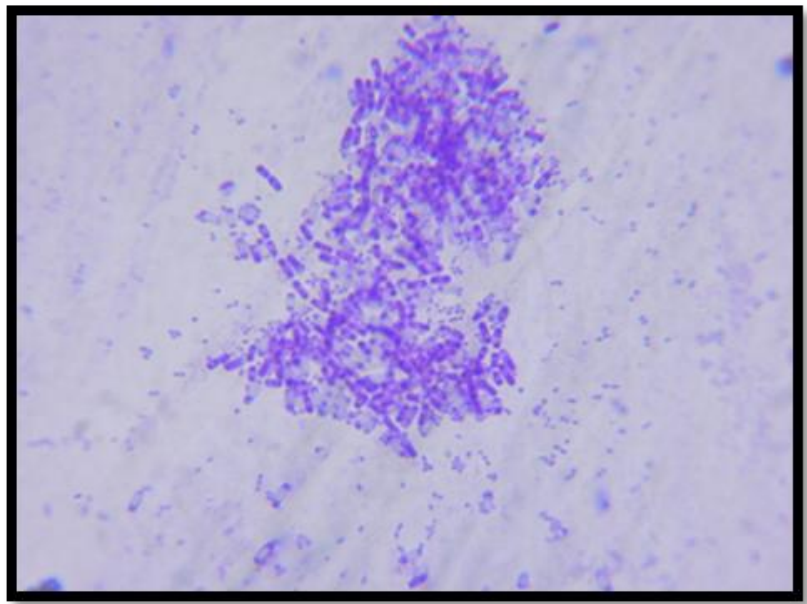


Fig.4 Color production in citrate utilization test indicates positive test)

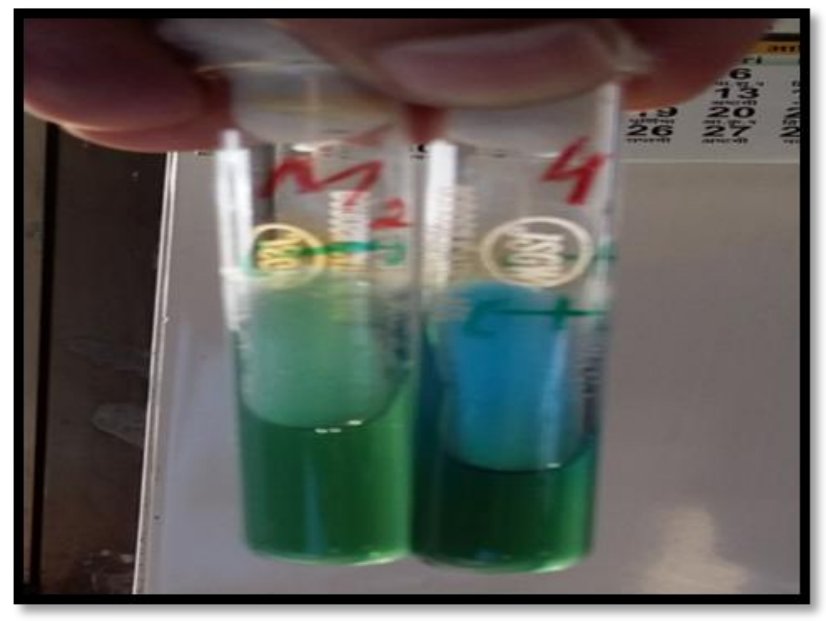

Fig.5 Motility test (haze around stab by motile bacteria)

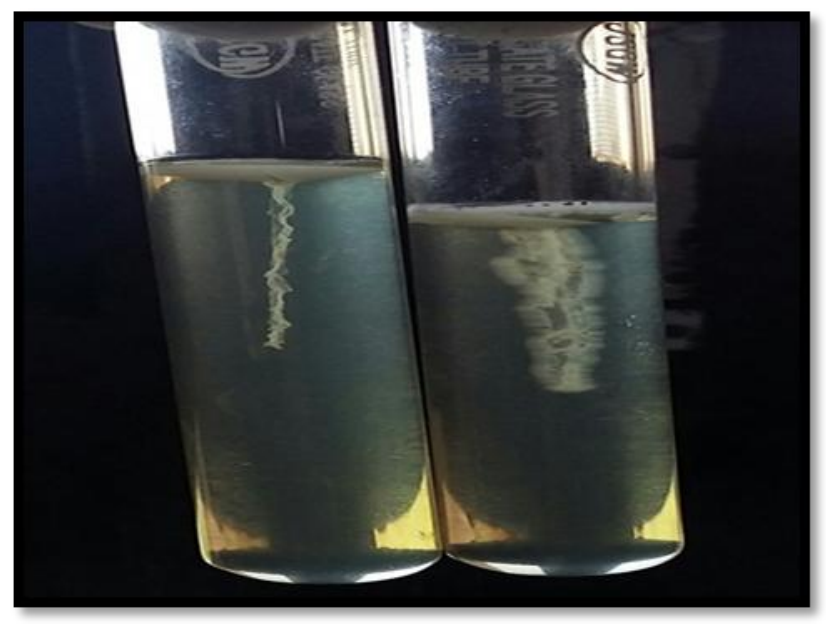

Fig.6 B. cereus showing starch hydrolysis (zone around streak)

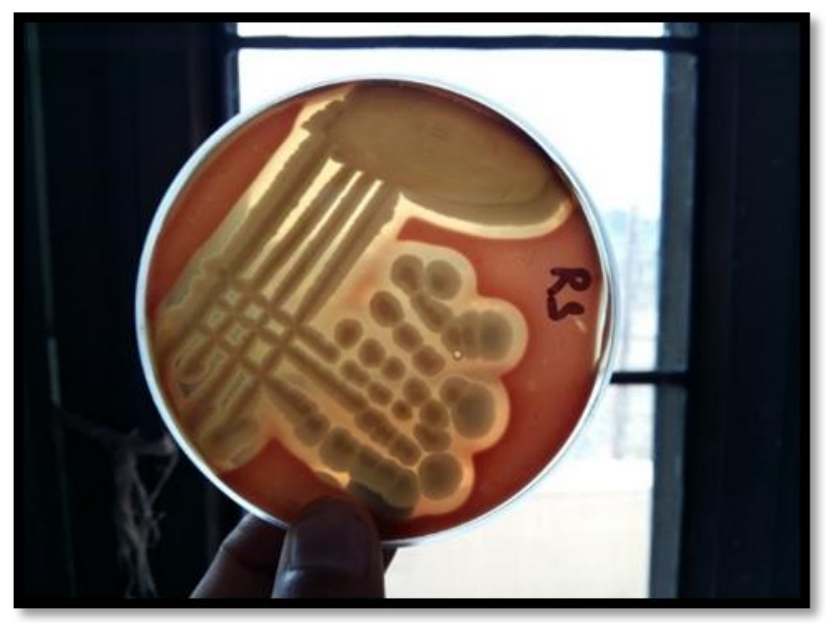


Fig.7 B. cereus showing $\beta$-haemolysis on sheep blood agar

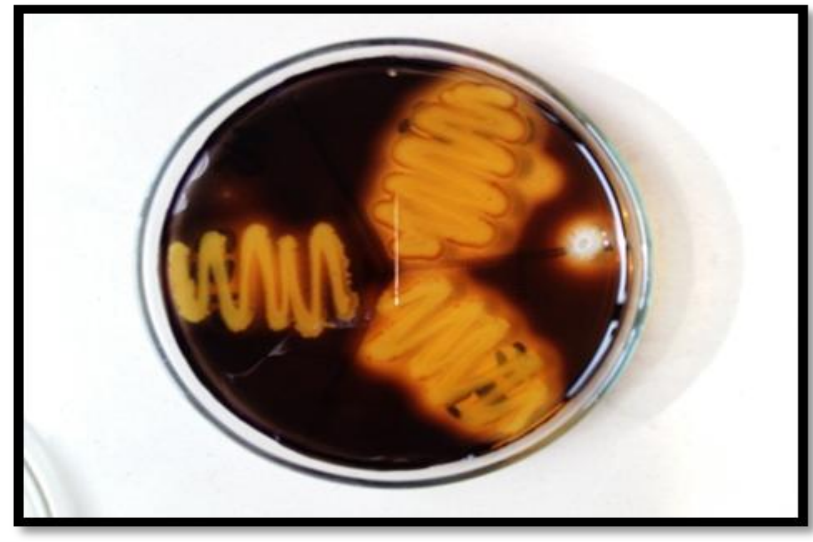

Fig.8 Nitrate reduction test (brick red color indicates positive test)

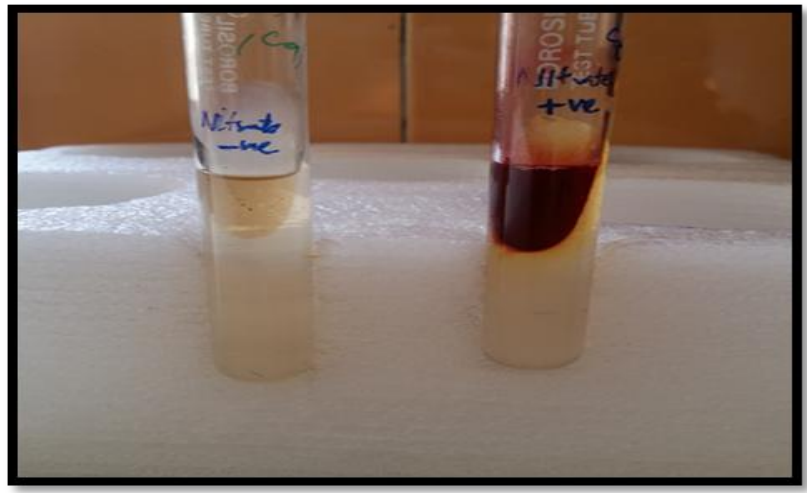

Fig.9 Voges-Proskauer test (Crimson red ring is indicative of positive test)

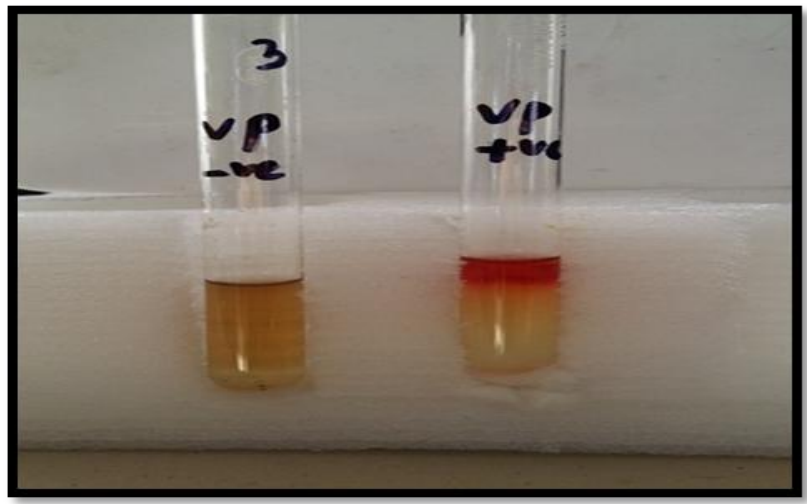

$B$. cereus is the bacterium responsible for $B$. cereus food poisoning. An estimation of 27,400 food borne cases of $B$. cereus food poisoning occurs annually in the United States. There are two forms of the intoxication: one cause's diarrhea, starting from 6 to 15 hours after consumption, and the other causes vomiting and nausea, starting from 30 minutes to 6 hours after consumption. Symptoms in both forms last about 24 hours. Everyone is susceptible to $B$. cereus food poisoning. Some isolates of $B$. cereus can grow at refrigerated temperature (Valeroa et al., 2007) and spore can survive at high temperature. This organism is known to resist even pasteurization process of milk (Novak et al., 2005). In India, presence of this 
organism has been reported in various food products including fish (Kamatet al., 1989). Till date, three different genes viz. hbla, bceT and entFM responsible for diarrhoeal enterotoxin production in $B$. cereus have been characterized (Asano et al., 1997). So far no study has been carried out to relate the presence of virulent genes and enterotoxin production in case of isolates of B. cereus from fish. Therefore, the present work was carried out to investigate the occurrence of enterotoxigenic B. cereus in fish, and also to study the relationship between diarrhoeal enterotoxin. The abilities of the spores and toxins of $B$. cereus to survive high temperatures and of certain psychotolerant strains to flourish at low temperatures make $B$. cereus a unique fish-borne pathogen. In comparison to other microorganisms, B. cereus is well versed with diversified characteristics like aerobic and facultative anaerobic growth, motility, psychrotrophic $\left(4^{\circ} \mathrm{C}\right)$ and thermophilic $\left(50^{\circ} \mathrm{C}\right)$ nature. These characteristics make $B$. cereus a unique and one of the most important food poisoning organisms. B. cereus makes its presence either in the form of vegetative cells or spores or toxins and is hence, anticipated from almost all foods of domestic consumption owing to its ubiquitous nature and adaptation to the environmental changes, thus posing a great public health threat. The effective use of quality control and safety measures during production/manufacture besides creating awareness among food handlers and consumers becomes necessary to ward off the menace of $B$. cereus and other food poisoning organisms.

\section{References}

Asano, S. I., Nukumizu, Y., Bando, H., Iizuka, T., Yamamoto, T. 1997. Cloning of novel enterotoxin genes from Bacillus cereus and Bacillus thuringiensis. Appl. Environ. Microbiol., 63: 1054-1057.

Kamat, A. S., Nerkar, D. P., Naif, P. M. 1989. Bacillus cereus in some Indian foods, Incidence and antibiotic, heat and radiation resistance. J Food Saf., 10: 3141.

Kotiranta, A., Haapasalo, M., Kari, K., Kerosuo, E., Olsen, I., Sorsa, T., Meurman, J. H., Lounatmaa, K. 1998. Surface structure, hydrophobicity, phagocytosis, and adherence to matrix proteins of $B$. cereus cells with and without the crystalline surface protein layer. Infect Immun., 66: 4895-4902.

Kotiranta, A., Lounatmaa, K., Haapasalo, M. 2000. Epidemiology and pathogenesis of B. cereus infections. Microbes Infect, 2: 189-198.

Novak, J. S., Call, J., Tomasula, P. and Luchansky, J. B. 2005. An assessment of pasteurization treatment of water, media, and milk with respect to Bacillus spores. J. Food Prot., 68: 751-7.

Ryan, K. J., Ray, C. G. 2004. Sherris Medical Microbiology, 4th edn. New York: McGraw Hill.

Seki, T., Chung, C. K., Mikami, H. and Oshima, Y. 1978. Deoxyribonucleic acid homology and taxonomy of the genus Bacillus. Int. J. Syst. Bacteriol., 28: 182189.

Valero, M., Hernandez-Herrero, L.A., Giner, M.J. 2007. Survival, isolation and characterization of a psychrotrophic Bacillus cereus strain from a mayonnaisebased ready-to-eat vegetable salad. Food Microbiology, 24: 671-677.

\section{How to cite this article:}

Rasool, U., Ajaz Ahmad, G.A. Badroo, Mir Mudasir, S. Fayaz and Mustafa, R. 2017. Isolation and Identification of Bacillus cereus from Fish and their Handlers from Jammu, India. Int.J.Curr.Microbiol.App.Sci. 6(8): 441-447. doi: https://doi.org/10.20546/ijcmas.2017.608.058 